\section{FURUNCULUS NASI A COMMON INFECTION IN ENT, YET SIGNIFICANT IN TERMS OF THE COMPLICATIONS THAT CAN ARISE IN THE ENDOCRANIUM}

\section{S. Stankovska-Kcheva ${ }^{1}$, A. Janchevska²,} H. Novevska-Markovska ${ }^{1}$, B. Kchev ${ }^{3}$

${ }^{1}$ ENT Department, Health Center Skopje, ${ }^{2}$ Endocrinology and Genetics, University Children's Hospital Skopje, ${ }^{3}$ Medical Faculty Skopje, Skopje, FYR Macedonia

Background and aims: To present this seemingly mild disease of the nose localized in the vestibulum and apex nasi, but here through the vein anastomose of $v$. angularis and the v. ophtalmica in the sinus cavernosum, where thrombosis can be caused. Hence, it should be timely diagnosed, treated and prevented for the process to stop spreading.

Methods: The diagnosis is made on the basis of the clinical picture, nose examination, frontal rhinoscopy, microbiological findings, hemogram, ophthalmic examination and CT of the endocranium.

Results: Children who were monitored for the duration of one year showed that in $10 \%$ of the whole number, the process had expanded to the v.ophtalmica, thanks to the right antibiotic treatment. The length of the treatment was approximately 7 days and the most common isolated carriers were: Staphilococcus Aureus and Streptococcus Piygenus.

Conclusions: In order to avoid the complications that are life-endangering, timely diagnosis and treatment is most significant.

\section{8}

\section{HIGH RESOLUTION COMPUTERIZED TOMOGRAPHY OF THE LUNGS IN CASES OF ACUTE SCHISTOSOMIASIS}

N.C.L. Petribu ${ }^{1}$, M.D.C.M. Duarte ${ }^{1}$,

E.J. Costa e Silva ${ }^{1,2}$, A.L.C. Domingues ${ }^{3}$,

\section{J.B. Correia ${ }^{1,4}$}

${ }^{1}$ Instituto de Medicina Integral Professor

Fernando Figueira, ${ }^{2}$ Faculdade Pernambucana de Saude, ${ }^{3}$ Universidade Federal de Pernambuco,

${ }^{4}$ Universidade de Pernambuco, Recife, Brazil

Background and aims: to describe abnormalities observed through high-resolution computerized tomography of the lungs of patients with acute schistosomiasis.
Methods: A series of 14 cases with acute schistosomiasis who underwent high-resolution computerized tomography of the lungs during the occurrence of an epidemic outbreak of the disease in Ipojuca, Pernambuco, Brazil, is described.

Results: High-resolution computed tomography revealed that all patients exhibited some degree of abnormality. The most frequent findings were nodules, in 13, and ground-glass opacity, in ten cases. The nodules were multiple, bilateral and more frequent in the middle and lower thirds of the lungs. The halo sign was found in five cases. Ground-glass opacity predominated in the middle and upper thirds of the right lung and the upper third of the left lung. In the ten patients with ground-glass opacities, these were only peripheral in all but one case, who also presented central opacities. Tomographic follow up was carried out on the one hospitalized patient, who had diffuse nodules and multiple peripheral and migratory ground-glass opacities associated to a thickening of the intralobular interstitium.

Conclusions: The present study reveals that ground-glass opacity is a transitory but frequent finding and proposes that acute schistosomiasis should be part of the differential diagnosis in patients with a suggestive clinical history.

\section{9}

EPIDEMIOLOGICAL PROFILE OF THE A (H1N1) PANDEMIC INFLUENZA IN THE STATE OF SAO PAULO, BRAZIL, FOR THE APRIL-SEPTEMBER 2009 TIMEFRAME

T.R.M.P. Carvalhanas ${ }^{1}$, A.F. Ribeiro ${ }^{1}$, A.L.F. Yu ${ }^{1}$, M.I.G. Okai ${ }^{1}$, M.C.S. Timenetsky ${ }^{2}$, C.M.S.S. Aranda ${ }^{3}$, C. Sacchi ${ }^{2}$

${ }^{1}$ Secretary of Health, Epidemiological Surveillance Center, ${ }^{2}$ Secretary of Health, Institute Adolfo Lutz, ${ }^{3}$ Secretary of Health, Center for Disease Control, Sao Paulo, Brazil

Background: On April 2009, the emergence of a new influenza virus strain set the stage for the first pandemic in the 21st century. We have analyzed the epidemiological profile of the $\mathrm{A} / \mathrm{H} 1 \mathrm{~N} 1$ pandemic influenza virus - the reported number of cases and deaths, confirmed by lab tests. The geographical scope of the analysis comprised the state of Sao Paulo, Brazil, during the Autumn-Winter season.

Methods: Epidemiological data was obtained from the National System of Acute Notifications which aggregates reported cases and are analyzed with 
the Epi Info/Win and Excel software. Laboratory confirmation tests were processed at Adolfo Lutz Institute in São Paulo, using real-time reverse transcriptase-polimerase chain reaction in nasal or oropharyngeal specimens.

Results: There were 25,082 reported cases still September 2009 , from these, $53 \%$ had ARS criteria, $29 \%$ influenza like illness. Among the 13,651 cases with ARS, $28 \%$ were positive for Influenza A(H1N1) and $4 \%$ for seasonal flu. The majority of reported and confirmed cases were notified in July and August, declining in September. Infants $\leq 24$ months and young adults 20-29 years of age were the groups more affected. Case fatality rates were greater in children $\leq 2$ years and adults (20-59 y).

Cases tested positive for $\mathrm{A}(\mathrm{H} 1 \mathrm{~N} 1)$ varied from 20 $35 \%$ within this period. High risk groups included children $\leq 24$ months and young adults, chronic pulmonary disease, smokers, metabolic disease and pregnant women.

Conclusion: The characteristics and evolution of the cases were similar to those occurring in the northern hemisphere, predominant circulation of the pandemic influenza virus.

\section{0}

\section{HOSPITALIZED PATIENTS WITH H1N1 INFLUENZA VIRUS INFECTION DURING PREGNANCY IN TWO PUBLIC HOSPITAL IN PORTO ALEGRE, BRAZIL}

M. Foresti Jiménez¹ ${ }^{1}$ P. El Beitune ${ }^{2}$, M. Pontremoli Salcedo², A. Veleda Von Ameln ${ }^{3}$, F. Pinto Mastalir ${ }^{2}$, L. Desimon Braun ${ }^{2}$

${ }^{1}$ Universidade Federal de Ciências da Saúde de Porto Alegre (UFCSPA). Hospital Fêmina, Grupo Hospitalar Conceição. Maternidade MárioTotta, Complexo Hospital Santa Casa, ${ }^{2}$ Universidade Federal de Ciências da Saúde de Porto Alegre (UFCSPA). Maternidade MárioTotta, Complexo Hospital Santa Casa, ${ }^{3}$ Hospital Fêmina, Porto Alegre, Brazil

Background and aims: The influenza virus H1N1 has been identified as the cause of a new pandemic of influenza in 2009. Pregnant women are at especially high risk for the development of complications of H1N1 influenza A. As the epidemics that preceded the current one, it affects more severely the pregnant women. We described clinical and epidemiologic characteristics of pregnant and postpartum patients who were hospitalized with $\mathrm{H} 1 \mathrm{~N} 1$ influenza as well as underlying conditions besides pregnancy that could place them at increased risk for intensive care unit (ICU) admission.

Methods: Retrospective cohort study with 58 patients hospitalized with influenza H1N1 in any gestational age (GA) or in postpartum period. We accessed maternal and fetal outcomes. We used Fisher's exact test and logistic regression.

Results: Antiviral drug was used in all patients. ICU admission was required in $13.8 \%$. There was no maternal death. ICU admission was not increased in patients with advanced GA and presence of comorbidities ( $P=0.66$ and 0.39 , respectively). We used logistic regression using ICU admission as the end point, and comorbidity and advanced GA as the study factor and we found no greater risk related with advanced GA or comorbidities ( $P>0.10)$.

Conclusions: Our research confirmed a relationship between precocious introduction of oseltamivir and lower mortality rate as we had no maternal death when $100 \%$ were treated. Not even with comorbidities and advanced GA pregnant women had increased ICU admission. It probably happened because we studied a young group of patients with less severe comorbidities.

\section{1}

\section{BACTERAEMIA AND ANTIBIOTIC USE IN SEVERE RESPIRATORY SYNCYTIAL VIRUS INFECTIONS}

\author{
A. Bouziri, A. Khaldi, S. Belhadj, A. Hamdi, \\ K. Menif, N. Ben Jaballah \\ Children's Hospital of Tunis, Tunis, Tunisia
}

Aims: To determine the frequency of and the risk factors for bacteraemia in infants hospitalized in the pediatric intensive care unit (PICU) with respiratory syncytial virus (RSV) infection and to precise the current use of antibiotics in these patients.

Methods: Retrospective study of infants, aged 0-24 months, admitted to a pediatric intensive care unit with proven RSV infection over a nine year period (2000-2008). Infants with concurrent bacteraemia and RSV infection were identified, and risk factors for bacteraemia were identified in univariate then in multivariate analysis (logistic regression model). The use of antibiotics in these infants was also precised. 